DOI: 10.12957/demetra.2017.23577

\title{
Perfil socioeconômico, demográfico e alimentar dos usuários do restaurante popular de Juiz de Fora, MG
}

\section{Socioeconomic, demographic and eating profile of Popular Restaurant's customers in Juiz de Fora, MG}

\author{
Rafaela Caroline Ladislau Nery Assunção \\ Paula Venturini Bastos ${ }^{\prime}$ \\ Bruna Pires Luz Silva' \\ Nathércia Percegoni' \\ Larissa Loures Mendes ${ }^{2}$ \\ Mirella Lima Binoti

\begin{abstract}
1 Universidade Federal de Juiz de Fora, Departamento de Nutrição. Juiz de Fora-MG, Brasil.

2 Universidade Federal de Minas Gerais, Departamento de Nutrição. Belo Horizonte-MG,
\end{abstract} \\ Brasil. \\ Correspondência / Correspondence \\ Mirella Lima Binoti \\ E-mail: mirella.binoti@ufjf.edu.br
}

\section{Resumo}

Objetivo: Descrever o perfil socioeconômico, demográfico e alimentar dos usuários do Restaurante Popular de Juiz de Fora - MG. Metodologia: Estudo descritivo transversal realizado no Restaurante Popular Yedda Duarte Gomes, situado na cidade de Juiz de Fora - MG. Foram aplicados questionários a 266 usuários mediante a assinatura do Termo de Consentimento Livre e Esclarecido, na saída do restaurante. Resultados e Discussão: A maioria dos usuários era do sexo feminino, idade média de 45,33 anos, havia cursado do $1^{\circ}$ ao 3 o grau do ensino médio, inseridos no mercado de trabalho, possuía residência fixa e renda média de 1,33 salário mínimo. A maior frequência ao restaurante foi de três a cinco vezes na semana (60,5\%); o motivo que mais influenciou na escolha do estabelecimento foi o preço (68\%); 36,8\% estavam no trabalho antes de ir ao restaurante; os alimentos regularmente consumidos eram: feijão $(87,6 \%)$, verduras e legumes $(61,7 \%)$, leite $(55,6 \%)$, frutas $(51,9 \%)$, frango/ galinha (22,6\%), alimentos doces $(21,4 \%)$, carne vermelha $(20,7 \%)$ e suco de fruta natural (20,7\%). O Restaurante Popular apresentou frequentadores que trabalhavam em suas imediações e moradores de rua $(0,8 \%)$. Conclusão: O Restaurante popular estudado atende às recomendações do Ministério do Desenvolvimento Social e Combate à Fome, quanto à oferta de refeições prontas e saudáveis a preço acessível, em local confortável e de fácil acesso, destinadas ao público em estado de insegurança alimentar. O conhecimento dos usuários e seus hábitos alimentares são importantes para uma melhor gestão do Restaurante Popular, contribuindo para a Segurança Alimentar e Nutricional da população.

Palavras-chave: Segurança Alimentar e Nutricional. Restaurantes. Hábitos Alimentares. Classe Social. Renda. 


\section{Abstract}

Objective: To describe the socioeconomic, demographic and eating profile of Popular Restaurant's customers in Juiz de Fora - MG. Methods: Cross-sectional descriptive study, carried out at Popular Restaurant Yedda Duarte Gomes, located in the city of Juiz de Fora - MG. Questionnaires were applied to 266 users after they signed a consent form as they left the restaurant. Results and Discussion: Most customers were female, with mean age of 45.33 years; they had attended from 1st to 3rd grade in high school; they were active workers, had a fixed address and average income of 1.33 minimum wages. The higher frequency in the restaurant was 3 to 5 times a week $(60.5 \%)$; the reason that most influenced the choice to go to the restaurant was the price (68\%); $36.8 \%$ were at work before going to the restaurant; foods regularly consumed were: beans $(87.6 \%)$, vegetables $(61.7 \%)$, milk (55.6\%), fruits $(51.9 \%)$, chicken (22.6\%), sweets (21.4\%), red meat $(20.7 \%)$ and natural fruit juice (20.7\%). Customers of the Popular Restaurant were people who worked in the vicinity and also homeless people $(0.8 \%)$. Conclusion: The popular restaurant being studied meets the recommendations of the Ministry of Social Development and Fight against Hunger, as well as offers ready-made and healthy meals at affordable prices, in a comfortable and easily accessible place, to the public in a state of food insecurity. Knowledge and characterization of customers and their eating habits are important for better management of the Popular Restaurant, thus contributing to the food and nutritional security of the population.

Keywords: Food and Nutrition Security. Restaurants. Food Habits. Social Class. Income.

\section{Introdução}

A alimentação é um direito fundamental para garantia da sobrevivência e manutenção da saúde e dignidade das populações. O Direito Humano à Alimentação Adequada (DHAA) é um conceito que foi estabelecido originalmente no art. 25 da Declaração Universal dos Direitos Humanos, no qual é discutido o contexto da promoção do direito a um padrão adequado de vida. ${ }^{1}$ Já a Segurança Alimentar e Nutricional (SAN), com substancial objetivo de constituir e implementar políticas públicas baseadas nos princípios do DHAA e da soberania alimentar, consiste na realização do direito de todos ao acesso regular e permanente a alimentos de qualidade, em quantidade suficiente, sem comprometer o acesso a outras necessidades essenciais, tendo como base práticas 
alimentares promotoras de saúde que respeitem a diversidade cultural e que sejam ambiental, cultural, econômica e socialmente sustentáveis. ${ }^{2}$

Em 15 de setembro de 2006, foi sancionada a lei no 11.346, denominada Lei Orgânica de Segurança Alimentar e Nutricional (LOSAN), regulamentada pelo Decreto no 7.272/2010, que criou o Sistema Nacional de Segurança Alimentar e Nutricional (SISAN) com vistas a assegurar o DHAA dos diferentes segmentos da população, instituiu a Política Nacional de Segurança Alimentar e Nutricional (PNSAN) e estabeleceu os parâmetros para a elaboração do Plano Nacional de Segurança Alimentar e Nutricional (PLANSAN). Essa lei descreve que a alimentação adequada é direito fundamental do ser humano, devendo o poder público adotar as políticas e ações que se façam necessárias para promover e garantir a SAN da população. ${ }^{2,3}$

Dentre as diversas ações da política de SAN, está o Programa de Restaurantes Populares (RPs): uma das iniciativas integradas à rede de ações do Programa Fome Zero, política de combate à fome e exclusão social, estabelecida em $2003 .{ }^{4}$

O programa de instalação de RPs Públicos é gerido pelo Ministério do Desenvolvimento Social e Combate à Fome (MDS) e operado com recursos do Orçamento Geral da União (OGU). É destinado aos estados, aos municípios e ao Distrito Federal e busca apoiar, em cidades de médio e grande porte, a implantação e modernização de restaurantes públicos populares geridos pelo setor municipal/estadual. O objetivo do programa é ampliar a oferta de refeições prontas e saudáveis a preço acessível, em local confortável e de fácil acesso, destinadas, preferencialmente, ao público em estado de insegurança alimentar. O MDS recomenda que a produção mínima estimada para um equipamento desta natureza seja de mil refeições diárias, no horário do almoço, por, no mínimo, cinco dias da semana. ${ }^{4}$

O RP de Juiz de Fora - MG está localizado na área central da cidade, próximo a terminais de ônibus, o que permite o fácil acesso pela população de outros bairros e municípios. Funciona de segunda a sexta-feira, distribui almoço a $\mathrm{R} \$ 2,00$ no horário das $11 \mathrm{~h}$ às $14 \mathrm{~h}$, possui 324 lugares e produz, em média, 1.500 refeições ao dia. Dessas refeições, cerca de 300 são fornecidas a catadores de papel e moradores de rua, cadastrados pela Secretaria de Assistência Social (SAS), os quais almoçam sem custo, sendo a sua alimentação subsidiada pela prefeitura. A gestão do RP é responsabilidade de um grupo gestor, escolhido por meio de processo licitatório e tem como secretaria executiva (poder público local) a Secretaria de Agropecuária e Abastecimento (SAA). ${ }^{5}$

Nesse contexto, é importante conhecer o perfil dos usuários dos RPs a fim de compreender suas necessidades para um adequado planejamento do cardápio, das instalações e funcionamento das unidades e comprovar a eficiência do programa quanto a sua cobertura. ${ }^{6,7}$ Diante disso, o objetivo do presente estudo foi descrever o perfil socioeconômico, demográfico e alimentar dos usuários do RP da cidade de Juiz de Fora - MG, além de investigar a frequência e os motivos que os levam a frequentá-lo. 


\section{Metodologia}

Trata-se de um estudo descritivo transversal realizado no RP Yedda Duarte Gomes, situado na cidade de Juiz de Fora - MG. Calculou-se a amostra com base no total de refeições servidas por dia (1.500). Para o cálculo, utilizou-se a formula:

$$
\mathrm{n}=\left[\operatorname{EDFF}^{*} \mathrm{~Np}(1-\mathrm{p})\right] /[(\mathrm{d} 2 / \mathrm{Z} 21-\alpha / 2 *(\mathrm{~N}-1)+\mathrm{p} *(1-\mathrm{p})]
$$

em que

Tamanho da população - para o fator de correção da população finita ou fcp (N): 1.500

Frequência hipotética da população (p): 30\%

Limites de confiança (d): $5 \%$

Efeito do desenho (EDFF): 1

Escore padrão da distribuição normal (Z): (1,96 para 95\% de confiança)

Conforme resultado do OpenEpi, versão 3, calculadora de código aberto - SSPropo, a população amostral foi de 266 participantes. A unidade amostral do estudo foi definida com os seguintes critérios de inclusão: idade acima de 18 anos e menor ou igual a 65 anos, de ambos os sexos, incluindo analfabetos e moradores de rua.

Os dados demográficos e socioeconômicos foram coletados por meio de um questionário estruturado adaptado da pesquisa realizada pelo Ibope, sob encomenda do Ministério de Desenvolvimento Social e Combate à Fome, em 2005, aplicado para traçar o perfil dos usuários de RPs. ${ }^{8} \mathrm{O}$ questionário adaptado foi composto por parte das questões contidas no questionário original.

Para avaliação do perfil demográfico, foram utilizadas variáveis como: idade em anos completos, sexo (masculino e feminino), estado civil (casado / vive com outra pessoa, solteiro, separado / divorciado / viúvo), cidade e bairro onde moram (distribuídos por regiões) e se possuem residência fixa (sim ou não). Para o perfil socioeconômico, usou-se as variáveis: escolaridade (categorizada em analfabeto, $1^{\underline{a}}$ a $4^{\underline{a}}$ série do ensino fundamental, $5^{\underline{a}}$ a $8^{\underline{a}}$ série do ensino fundamental, $1^{\circ}$ ao $3^{\circ}$ grau do ensino médio, superior completo ou incompleto), renda pessoal e familiar (referidas pelo entrevistado), ocupação e meio de transporte utilizados para frequentar o estabelecimento (ônibus, carro, bicicleta, a pé ou motocicleta).

Para investigar o consumo alimentar, adaptou-se parte do questionário utilizado na vigilância de fatores de risco e proteção para doenças crônicas por inquérito telefônico (VIGITEL), incluindo questões como: "Em quantos dias da semana o (a) Sr (a) costuma comer feijão?"; "Em quantos dias da semana o (a) $\mathrm{Sr}$ (a) costuma comer pelo menos um tipo de verdura ou legume?"; "Em quantos 
dias da semana o (a) Sr (a) costuma comer carne vermelha?"; "Em quantos dias da semana o (a) Sr (a) costuma comer frango/galinha?"; entre outras. ${ }^{9}$

Já para a análise do perfil da alimentação e os hábitos de vida dos participantes, foram inferidas questões sobre: a frequência que realiza suas refeições no RP; o motivo para realizar a refeição no RP (preço, refeição saudável, localização do restaurante, entre outros citados pelos entrevistados); consumo de refeição em companhia de outra pessoa da família; questões sobre enfrentar fila para o acesso ao restaurante e tempo de permanência nessa fila; local onde os usuários têm o hábito de estar antes de ir ao RP; local de alimentação quando não têm a oportunidade de frequentar o RP durante a semana e finais de semana; a opinião dos usuários sobre o valor cobrado ser acessível ou não; a representatividade do valor gasto no orçamento mensal; a preocupação com a alimentação saudável; a quantidade de comida oferecida pelo restaurante ser o suficiente.

As preferências alimentares foram relatadas pelos entrevistados a partir de uma lista que permitia as respostas "sim" ou "não", considerando alimentos servidos ou não no RP. O consumo regular de frutas, feijão, legumes e verduras, leite, frango/galinha, alimentos doces, carne vermelha, suco de fruta natural, refrigerantes e sucos artificiais e de bebidas alcoólicas foi categorizado em cinco ou mais dias da semana, e o consumo desses alimentos foram utilizados como marcadores de padrões saudáveis e não saudáveis da alimentação. ${ }^{10}$ Quanto à prática de atividade física, quando confirmada, foi questionada a frequência e o tempo dessa atividade.

Tal questionário foi aplicado abordando o usuário, aleatoriamente, no momento em que este se retirava do estabelecimento, dentro do horário de funcionamento do RP, durante os meses de julho e agosto de 2015 .

Os usuários do restaurante que concordaram em participar da pesquisa receberam todas as informações sobre o estudo e assinaram o Termo de Consentimento Livre e Esclarecido. O estudo obteve aprovação do Comitê de Ética em Pesquisa com Seres Humanos da Universidade Federal de Juiz de Fora (Parecer $n^{\circ}$ 1.150.168). As informações coletadas para a realização da validação e análise foram transcritas para meio eletrônico.

Os dados foram descritos por meio da distribuição de frequências absolutas e relativas e foram processados e analisados por meio do programa Statistical Software for Professionals (STATA), versão 13.0 .

\section{Resultados e Discussão}

Os dados apurados revelam que a maioria dos usuários era do sexo feminino $(56,4 \%, \mathrm{n}=150)$, e a média das idades dos participantes foi de 45,33 anos ( $\pm 13,30$ anos). Esses resultados diferem da pesquisa para identificar e avaliar o perfil dos usuários de RPs, realizada, em 2008, pelo Centro 
de Estudos de Opinião Pública (CESOP)/ Fundação de Desenvolvimento da Unicamp-FUNCAMP e encomendada pelo MDS do restaurante de Belo Horizonte (rodoviária) e do RP do município de Campinas, na qual foi verificada maior frequência de pessoas do sexo masculino. ${ }^{6,11}$ Esse maior número de mulheres pode ser explicado pela pirâmide etária populacional de Juiz de Fora, na qual, na faixa etária de 45 a 49 anos, o número de pessoas do sexo feminino é bem maior que o do sexo masculino. ${ }^{12}$ Já em relação à idade, os resultados foram similares aos encontrados no estudo do RP do município de Campinas, que foi de 47,7 anos. ${ }^{6}$

Segundo o estado civil, a maioria dos usuários, 43,2\% ( $\mathrm{n}=115)$, relatou ser solteira, o que pode ser explicado devido ao fato de as pessoas que procuram o restaurante para se alimentar normalmente não possuírem alguém para preparar suas refeições..$^{13}$

A maioria dos usuários do restaurante, 88,7\% ( $\mathrm{n}=236)$, residia em Juiz de Fora e 11,3\% ( $\mathrm{n}=30)$, em outros municípios, mostrando que mesmo com a maioria dos frequentadores sendo moradores da cidade, o restaurante ainda recebia pessoas de outros municípios para almoçar. O RP atende a todas as regiões do município de Juiz de Fora (Tabela 1), no entanto, as mais relatadas pelos usuários foram: região leste, com 19,9\% ( $\mathrm{n}=53)$, e região norte, com 18\% ( $\mathrm{n}=48)$.

Com relação à moradia, 99,2\% $(\mathrm{n}=264)$ dos entrevistados disseram ter residência fixa, enquanto $0,8 \%(\mathrm{n}=2)$, não ter. A pesquisa foi realizada a partir de calculo amostral com base no total de frequentadores, que eram convidados, voluntariamente, a participar da pesquisa. Portanto, o percentual de entrevistados sem residência fixa pode ser explicado devido a esses usuários se recusarem a participar, por se sentirem envergonhados. Segundo Mattos \& Ferreira,,${ }^{14}$ os moradores de rua são, em sua maioria, estereotipados como "sujos e vagabundos", contribuindo assim para que esses se sintam humilhados e envergonhados, preferindo muitas vezes se isolarem. Porém, estudos afirmam que a maior parte da população de rua de Juiz de Fora (73\%) tem o hábito de frequentar instituições assistenciais para buscar suprimentos para suas necessidades diárias. ${ }^{15}$ E que 300 catadores de papel e moradores de rua encontram-se cadastrados na prefeitura de Juiz de Fora para almoçar gratuitamente no RP. ${ }^{5}$ No entanto, a identificação desses indivíduos é importante para saber mais informações sobre esses usuários e confirmar se realmente estão utilizando as instituições assistenciais a fim de satisfazerem suas necessidades básicas. Além disso, trata-se de uma população cada vez mais marcante nos grandes centros urbanos e também em cidades médias, como Juiz de Fora, com crescente número de pessoas vivendo em condições de grandes privações nas ruas. ${ }^{16}$

Os dois meios de locomoção mais utilizados pelos usuários para chegar ao RP eram o ônibus $(52,3 \%, \mathrm{n}=139)$ e a pé $(45,9 \%, \mathrm{n}=122)$ (Tabela 1). Esses resultados são semelhantes aos da pesquisa do RP de Campinas, na qual os dois meios de locomoção mais utilizados eram o ônibus $(75,2 \%)$ e a pé $(23,3 \%){ }^{6}$ Quase metade dos usuários não precisava utilizar meios de transporte para chegar ao RP, indicando que a localização do mesmo é favorável para os frequentadores, e está de acordo 
com o relatado no roteiro para implantação de RP de 2007, no qual é estabelecido que os locais de implantação devem garantir que os usuários não tenham que utilizar meios de transporte para os deslocamentos no horário de almoço e devem se localizar em áreas centrais das cidades, que, de preferência, também sejam próximas a locais de transporte de massa. ${ }^{4}$

Quanto à escolaridade, 45,1\% (n=120) dos usuários tinham cursado do $1^{\circ}$ ao $3^{\underline{0}}$ grau do ensino médio, semelhante ao verificado pela pesquisa encomendada pelo MDS (2008), que constatou que a maioria dos usuários concluiu e/ou iniciou o ensino médio. ${ }^{11}$ A escolaridade é um importante dado para avaliar o perfil de uma população, pois está relacionada à inserção no mercado de trabalho, indicando que a mão de obra necessita cada vez mais de maiores graus de escolaridade para competir com mais vantagens por empregos. Isso mostra que as pessoas estão buscando cada vez mais um nível superior de escolaridade, o que no futuro poderá propiciar melhores empregos e maior renda. ${ }^{17}$ No Plano Municipal de Saúde de Juiz de Fora (2014-2017), pode-se ver que o Índice de Desenvolvimento Humano (IDH) de 2010 aponta para um crescimento maior nos graus de escolaridade da população de Juiz de Fora. ${ }^{12}$

Os percentuais de renda que mais se destacaram foram: mais de 1 a 3 salários mínimos, apresentado por 46,2\% (n=123) dos entrevistados, e até 1 salário mínimo, verificado em 37,2\% (n= 99) (Tabela 1), totalizando uma média de 1,33 salários mínimos, sendo menor que a média da renda dos entrevistados da pesquisa no Restaurante de Campinas, que foi de 2,4 salários mínimos. ${ }^{6,18}$

De acordo com alguns dos resultados encontrados, como a escolaridade e a renda, podemos observar que o restaurante não abrange somente indivíduos com níveis socioeconômicos muito baixos, mas um público diversificado, que encontra no RP uma opção para se alimentar de forma adequada por um preço justo. E segundo a pesquisa encomendada pelo MDS (2008), que encontrou perfil semelhante em seus entrevistados, esse resultado deve ser interpretado como um desdobramento e não como uma mudança do objetivo principal do programa, e que a rotulagem desses frequentadores como sendo de baixa renda tende a estigmatizar os pobres que utilizam esse programa, criando nas demais classes sociais uma visão negativa dessas políticas. ${ }^{11}$

Dos usuários do RP de Juiz de Fora, 53,8\% (n= 143) trabalhavam, enquanto 27,8\% (n= 74) não trabalhavam e 18,4\% (n= 49) são aposentados. Entre os que não trabalhavam, estão estudantes que aproveitavam o RP como uma oportunidade de se alimentar corretamente por um baixo preço. Segundo Leal, ${ }^{19}$ com a crescente urbanização e industrialização, as pessoas optam por comer fora de casa devido à falta de tempo disponível para o preparo da sua alimentação.

Os resultados da avaliação do perfil alimentar e hábitos de vida mostraram que, entre os entrevistados, a maioria, 60,5\% $(\mathrm{n}=161)$, frequentava o RP três a cinco vezes na semana, 16,5\% $(\mathrm{n}=44)$ afirmaram frequentar o estabelecimento uma a duas vezes na semana, 9,8\% (n=26), uma a duas vezes/mês, $9 \%(\mathrm{n}=24)$ raramente comiam nesse local e 4,1\% $(\mathrm{n}=11)$ relataram ser a primeira 
vez no dia da entrevista. Resultados semelhantes foram obtidos na pesquisa Ibope, na qual $45 \%$ dos usuários frequentavam sempre, e $16 \%$, duas a três vezes na semana. ${ }^{20} \mathrm{~A}$ regularidade da ida ao restaurante é um dado importante em razão de assegurar a essas pessoas a contribuição nutricional necessária a uma vida saudável. ${ }^{21}$

O motivo que mais influenciou a escolha de realizar as refeições no RP foi o preço acessível, $68 \%$ ( $\mathrm{n}=181)$, no valor de $\mathrm{R} \$ 2,00$, seguido por alimentação saudável $(23,7 \%, \mathrm{n}=63)$ e qualidade $(19,9 \%, n=53)$ (Tabela 1). Um estudo realizado pelo Ibope observou que $78 \%$ dos entrevistados referiram realizar a refeição nos RPs principalmente pelo fator financeiro; já em Fortaleza - CE, $75 \%$ das pessoas destacavam a qualidade da refeição como fator determinante para sua escolha. ${ }^{21}$

Tabela 1. Perfil socioeconômico e demográfico dos frequentadores do Restaurante Popular Yedda Duarte Gomes e motivos para frequentá-lo. Juiz de Fora-MG, 2015.

\begin{tabular}{lcc}
\hline \multicolumn{1}{c}{ Perfil dos usuários } & n & Porcentual (\%) \\
\hline Regióes onde moram em Juiz de Fora & 39 & 14,7 \\
Centro & 53 & 19,9 \\
Leste & 16 & 6,0 \\
Nordeste & 48 & 18,0 \\
Norte & 8 & 3,0 \\
Oeste & 41 & 15,4 \\
Sudeste & 29 & 10,9 \\
Sul & & \\
Meio de transporte até o RP & 139 & 52,3 \\
Onibus & 6 & 2,3 \\
Bicicleta & 122 & 45,9 \\
A pé & 9 & 3,4 \\
Carro & 1 & 0,4 \\
Motocicleta & 0 & 0 \\
Não Opinou & & \\
\end{tabular}


Continuação da Tabela 1

\begin{tabular}{lcc}
\hline \multicolumn{1}{c}{ Perfil dos usuários } & n & Porcentual (\%) \\
\hline Renda & 4 & 1,5 \\
Mais de 5 SM* & 32 & 12 \\
Mais de 3 a 5 SM* & 123 & 46,2 \\
Mais de 1 a 3 SM* & 99 & 37,2 \\
Até 1 SM* & 6 & 2,3 \\
Não tem Rendimento Pessoal & 2 & 0,8 \\
Não Opinou & & \\
Motivos para almoçar no RP & 181 & 68 \\
Preço & 92 & 34,6 \\
Outros & 63 & 23,7 \\
Refeição Saudável & 53 & 19,9 \\
Qualidade & 17 & 6,4 \\
Localização do RP & 4 & 1,5 \\
Nenhum outro motivo & 3 & 1,1 \\
Não opinou & & \\
\hline
\end{tabular}

*SM = Salário Mínimo

O Programa Restaurantes Populares é parte integrante das ações de SAN desenvolvidas pelo governo federal e desempenha um papel social de extrema relevância, pois, como política pública, visa garantir e fornecer segurança alimentar à população de baixa renda por meio do oferecimento de refeições prontas, nutricionalmente balanceadas, com diversos cardápios originados de processos seguros de manipulação, a baixo preço e servidas em locais apropriados. ${ }^{18}$

Em relação ao consumo de refeição em companhia de outra pessoa da família, 58,3\% (n=155) afirmaram realizar suas refeições sozinhas, $14,3 \%(\mathrm{n}=38)$ referiram a presença do cônjuge (marido/ esposa/companheiro) e 11,3\% ( $\mathrm{n}=30)$, a presença de filhos. Verificou-se ainda que 96,2\% ( $\mathrm{n}=256)$ dos entrevistados relataram enfrentar fila para serem atendidos e $44 \%(n=117)$ esperavam de 10 a 20 minutos para receberem a refeição. 
Outro aspecto avaliado dis respeito ao local onde os usuários entrevistados tinham o hábito de estar antes de ir para o RP. Foi observado que a maioria, 36,8\% $(\mathrm{n}=98)$, encontrava-se no trabalho, $27,8 \%(n=74)$, em casa, 22,9\% $(n=61)$, em outro local e $12 \%(n=32)$, na rua. Dado semelhante ao encontrado na pesquisa do MDS, de 2005, na qual 37\% dos usuários estavam no trabalho antes de ir ao restaurante. A necessidade de realizar refeições fora da residência está relacionada às grandes distâncias entre a moradia e o local onde estão concentradas e desenvolvidas as atividades produtivas, associadas ao alto custo do deslocamento do trabalho para residência, bem como a insuficiência de renda e o baixo poder aquisitivo da população. ${ }^{20}$

Quanto ao local de alimentação quando não tinham a oportunidade de frequentar o RP durante a semana, a maioria, $61,7 \%(\mathrm{n}=164)$, respondeu que realizava suas refeições em casa ou trazia de casa, 25,9\% $(n=69)$, em restaurantes comerciais, 6,8\% $(n=18)$ iam a lanchonetes e 5,3\% $(n=14)$ não iam a outro local, ficando sem se alimentar. Nos finais de semana, $85 \%(n=226)$ dos entrevistados faziam suas refeições em casa e 12,8\% (n=34), em restaurantes comerciais. Na pesquisa do MDS, realizada para averiguar o perfil dos usuários do Programa Restaurantes Populares em cinco capitais brasileiras (São Paulo, Rio de Janeiro, Brasília, Salvador e Belo Horizonte), 36\% afirmaram comer em casa. ${ }^{22}$

Com relação à opinião sobre o valor atual cobrado, notou-se que 98,5\% (n=262) concordavam que era acessível, sendo esta uma das preocupações dos formuladores de ações públicas e um dos objetivos do programa dos RPs brasileiros. ${ }^{20} \mathrm{E}$ quanto à representatividade desse valor gasto nas refeições do RP no orçamento mensal, foi percebido que 54,9\% (n=146) afirmaram que esse valor era baixo, 11,3\% ( $n=30)$ disseram ser muito baixo e outros 28,9\% $(n=77)$ asseguraram que o valor não era nem alto nem baixo. Estes resultados também são similares aos encontrados no estudo do MDS. ${ }^{20}$ Dos entrevistados, $82 \%$ (n=218) tinham preocupação com uma alimentação saudável, e para $98,5 \%$ ( $n=262)$, a quantidade de comida oferecida pelo restaurante era suficiente para sua refeição. Quanto à preferência das preparações servidas pelo RP (Tabela 2), a opção "gosto de todas" foi citada por 22,9\% (n=61), seguida da preparação frango a passarinho, $15 \%(n=40)$. Em relação aos alimentos que menos gostam, o bife de hambúrguer foi relatado por $12 \%$ (n=32) e está entre os pratos que menos agradam (Tabela 2). 
Tabela 2. Alimento preferido e alimento que menos gosta, servidos pelo Restaurante Popular Yedda Duarte Gomes. Juiz de Fora-MG, 2015.

\begin{tabular}{lcc|lcc}
\hline \multicolumn{1}{c}{ Alimento preferido } & & \multicolumn{2}{c}{ Alimento que menos gosta } \\
\hline Arroz & $\mathbf{n}$ & $\boldsymbol{\%}$ & \multicolumn{1}{c}{ Alimento } & $\mathbf{n}$ & $\%$ \\
Bife & 15 & 5,6 & Bife de hambúrguer & 32 & 12 \\
Carne cozida & 9 & 3,4 & Caldos/sopas & 10 & 3,8 \\
Farofa & 14 & 5,3 & Carne & 5 & 1,9 \\
Feijão & 7 & 2,6 & Farofa & 6 & 2,3 \\
Frango & 18 & 6,8 & Fígado de boi & 15 & 5,6 \\
Frango a passarinho & 11 & 4,1 & Fígado de galinha & 20 & 7,5 \\
Gosta de todas & 40 & 15 & Gosta de todas as opções & 54 & 20,3 \\
Macarrão & 61 & 22,9 & Macarrão & 7 & 2,6 \\
Não gosta de nenhuma & 1 & 0,4 & Não gosta de nenhuma & 26 & 9,8 \\
Não opinou & 7 & 2,6 & Não opinou & 10 & 3,8 \\
Saladas & 18 & 6,8 & Repolho & 7 & 2,6 \\
\hline
\end{tabular}

Considerando as refeições diárias, os alimentos mais presentes, independente do que era servido pelo RP, eram: arroz $(99,2 \%, \mathrm{n}=264)$, feijão $(94,7 \%, \mathrm{n}=252)$, saladas $(90,2 \%, \mathrm{n}=240)$, frango $(89,1 \%$, $\mathrm{n}=237$ ) e verduras $(87,6 \%, \mathrm{n}=233)$ (Figura 1). Os resultados mostraram que a maioria dos usuários consumia diariamente todos os grupos de alimentos, de acordo com a divisão estabelecida pelo Guia Alimentar para a População Brasileira, publicado em 2014, no qual os grupos alimentares são divididos da seguinte forma: cereais, raízes e tubérculos, carnes e ovos, leites e queijos, legumes e verduras, frutas e feijões. ${ }^{23}$ 


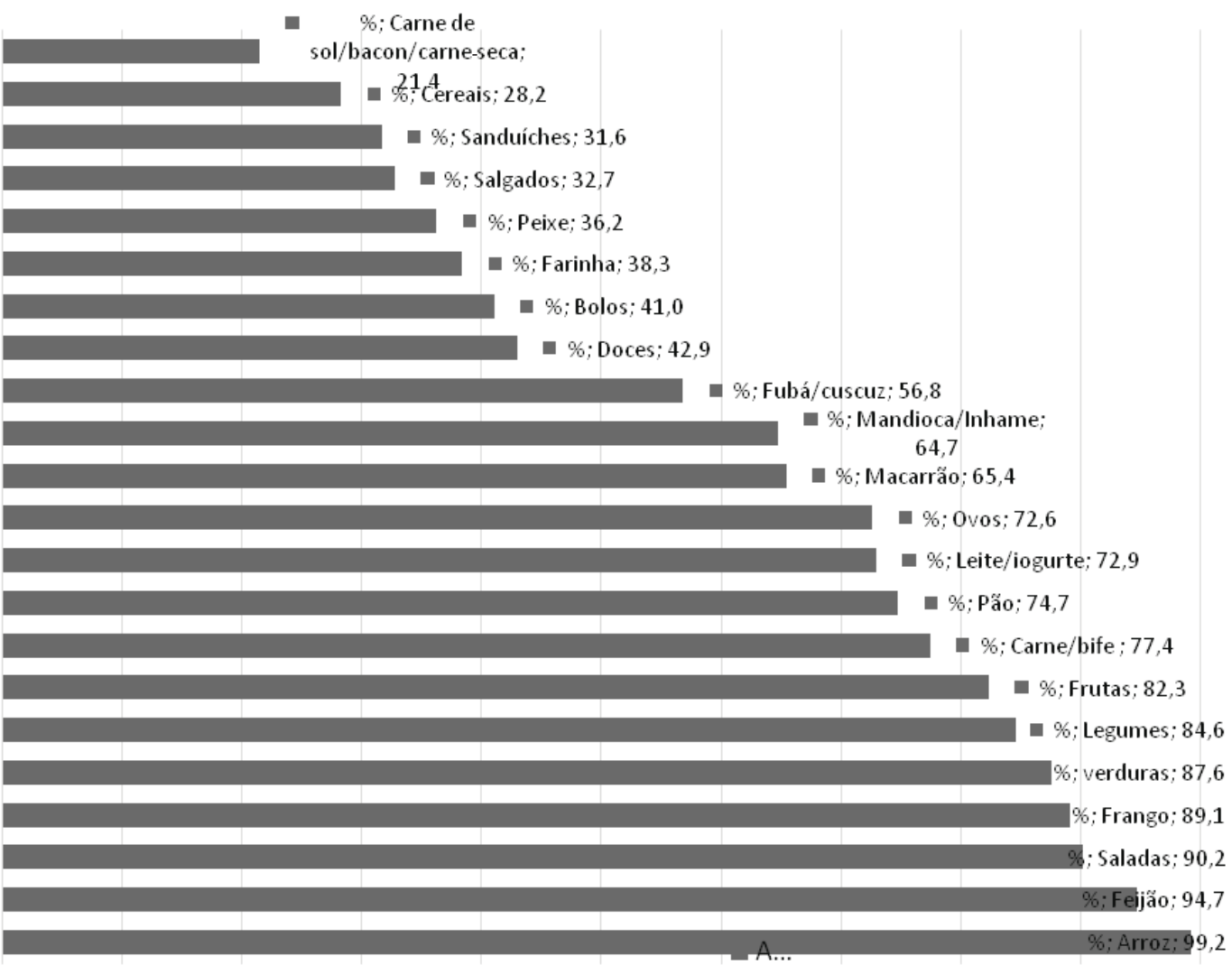

Figura 1. Alimentos mais consumidos, independente do que é servido pelo Restaurante Popular Yedda Duarte Gomes. Juiz de Fora-MG, 2015.

A análise da frequência de consumo alimentar mostrou que, quanto ao de frutas, $51,9 \%$ (n=138) dos entrevistados comiam esses alimentos cinco ou mais vezes na semana. Do número total de indivíduos entrevistados, 46,2\% ( $n=122)$, apenas uma vez ao dia, 31,8\% ( $n=84)$, duas vezes ao dia e 22\% (n=58), três ou mais vezes ao dia. No estudo realizado, em 2011, na Cidade de Brasília, para avaliar características e razões de consumo de frutas e hortaliças e o conceito de alimentação saudável de adultos residentes na cidade, $69,5 \%$ dos entrevistados afirmaram a ingerir frutas cinco ou mais vezes por semana. ${ }^{24}$ 
Entre os alimentos mais consumidos regularmente (cinco vezes ou mais na semana), estavam: feijão $(87,6 \%, n=233)$, verduras e legumes $(61,7 \%, n=164)$, leite $(55,6 \%, n=148)$, frango/galinha $(22,6 \%, n=60)$, alimentos doces $(21,4 \%, n=57)$, carne vermelha $(20,7 \%, n=55)$ e suco de fruta natural $(20,7 \%, \mathrm{n}=55)$. Um estudo realizado com dados do Sistema VIGITEL 2014 mostrou que o consumo de feijão permanece em $66,1 \%$ da população brasileira, e com maior frequência, $81,3 \%$, na cidade de Belo Horizonte, Minas Gerais. ${ }^{10}$

Quando questionados sobre o consumo de refrigerantes e sucos artificiais, essas bebidas eram consumidas cinco ou mais vezes na semana por 50,8\% (n=135). De todos os entrevistados, 56,6\% $(\mathrm{n}=137)$ disseram tomar um copo ou lata, 25,2\% $(\mathrm{n}=61)$, dois copos ou latas, 9,9\% $(\mathrm{n}=24)$, quatro copos ou latas, $5,4 \%(n=13)$, seis ou mais copos ou latas e 2,9\% $(n=7)$, cinco copos ou latas. O consumo de bebida alcoólica foi relatado por $32 \%(n=85)$ dos entrevistados, sendo que 5,9\% (n=5) afirmaram a frequência de cinco ou mais vezes por semana.

Quanto à prática de atividade física, 52,6\% (n=140) eram inativos, aqui considerados aqueles que nos últimos três meses não praticaram nenhum tipo de exercício ou esporte. Dos 47,4\% (n=126) ativos, $41,6 \%(n=52)$ relataram a frequência de cinco ou mais vezes na semana e $64,8 \%(n=81)$, que essa atividade durava cerca de 60 minutos ou mais.

Estes resultados demonstram que o consumo de feijão, frutas, verduras e legumes, marcadores de hábitos alimentares saudáveis, ${ }^{10}$ estava presente na rotina alimentar da população estudada. Acredita-se que o RP pode influenciar positivamente a melhoria da alimentação diária dos estudados, pois oferta esses alimentos considerados saudáveis. Porém, hábitos considerados não saudáveis ${ }^{10}$ também faziam parte do perfil dos usuários do RP, já que pouco mais da metade da população estudada referiu consumir refrigerante e suco artificial cinco ou mais vezes na semana e boa parte relatou consumir alimentos doces, sendo estes os maiores contribuintes para a participação do açúcar adicionado no consumo alimentar. ${ }^{25} \mathrm{~A}$ prevalência de hábitos sedentários são marcadores que indicam um padrão de consumo não saudável. ${ }^{10}$

Entre as limitações do presente estudo, destaca-se que, por se tratar de um hábito desejável, a ingestão de frutas, verduras e legumes pode ter sido superestimada por conta dos entrevistados no relato das respostas de consumo desses alimentos. Além disso, todas as informações obtidas foram autorrelatadas, o que é passível de esquecimentos. Entretanto, pela frequência identificada, considera-se que esse tipo de erro de aferição tenha sido mínimo, pois as questões coletadas tratavam de eventos recentes.

Entre os aspectos positivos do presente estudo, ressalta-se a sua contribuição por meio da descrição e apresentação dos dados socioeconômicos, demográficos, de comportamento alimentar e hábitos praticados pelo público atendido no RP. Essas informações podem fornecer subsídios à tomada de decisões voltadas ao programa, tendo em vista a construção do novo RP do município. 


\section{Conclusões}

Com os resultados obtidos no presente estudo, foi possível concluir que o RP no município de Juiz de Fora é importante para a SAN de seus usuários, e para alguns, é a única alternativa de realizar pelo menos uma refeição completa ao dia e em horário adequado, de forma saudável e a baixo custo. $\mathrm{O}$ RP atende às recomendações do MDS, quanto à oferta de refeições prontas e saudáveis a preço acessível, em local confortável e de fácil acesso.

O RP Yedda Duarte Gomes apresentou como frequentadores indivíduos que trabalhavam em suas imediações, que se preocupavam em escolher alimentos saudáveis, que tinham como maior motivador para frequentar o estabelecimento o preço e que não eram somente pessoas de baixa renda, mas um público diversificado, fato interessante para que todos os segmentos sociais reconheçam a qualidade do programa.

Salienta-se a importância do conhecimento e caracterização do usuário e seus hábitos, para uma melhor gestão do RP, pois, com essas informações, é possível realizar o planejamento adequado do cardápio, contribuindo para as políticas publicas de SAN.

\section{Colaboradores}

Assunção RCLN e Bastos PV trabalharam em todas as etapas, desde a concepção do estudo, coleta de dados até a revisão da versão final do artigo; Mendes LL trabalhou na concepção do estudo, análises estatísticas e revisão da versão final do artigo; Binoti ML orientou e trabalhou em todas as etapas, desde a concepção do estudo até a revisão da versão final do artigo; Percegoni N e Silva BPL trabalharam na redação, edição e revisão da versão final do artigo.

Conflito de Interesses: Os autores declaram não haver conflito de interesses.

\section{Referências}

1. Organização das Nações Unidas. Declaração Universal dos Direitos Humanos. Rio de Janeiro: ONU; 2009. 17 p. Disponível em: http://www.onu.org.br/img/2014/09/DUDH.pdf

2. Brasil. Lei no 11.346, de 15 set. 2006, Cria o Sistema Nacional de Segurança Alimentar e Nutricional - SISAN com vistas em assegurar o direito humano à alimentação adequada e dá outras providências. Diário Oficial da União 18 set 2006.

3. Brasil. Ministério da Saúde. Secretaria de Atenção à Saúde. Departamento de Atenção Básica. Política Nacional de Alimentação e Nutrição. Brasília: Ministério da Saúde; 2012. 84 p.

4. Brasil. Ministério do Desenvolvimento Social e Combate à Fome. Restaurantes populares. Roteiro de implantação 2007. Brasília: MDS; 2007. 56 p. 
5. Juiz de Fora. Conselho Municipal de Segurança Alimentar. Resolução no 009, 24 abr. 2012, Dispõe sobre a gestão do Restaurante Popular de Juiz de Fora - MG. Juiz de Fora: Comsea; 2012.

6. Gobato RC, Panigassi G, Villalba JP. Identificação do perfil de usuários de um restaurante popular do Município de Campinas. Revista Segurança Alimentar e Nutricional 2010; 17(2):14-25.

7. Portella EDA, Basso C, Medina VB. Perfil do usuário do restaurante popular da Cidade de Santa Maria - RS. Disciplinarum Scientia 2013; 14(1):101-107.

8. Araújo FR, Santos DF, Araújo MAD. O direito humano à alimentação adequada promovido por políticas de acesso a alimentos: o caso da unidade Natal-RN do Projeto Café do Trabalhador. R Pol Públ. 2011; 15(2):267-276.

9. Brasil. Conselho Nacional de Segurança Alimentar e Nutricional. A segurança alimentar e nutricional e o direito humano à alimentação adequada no Brasil realização: indicadores e monitoramento: da Constituição de 1988 aos dias atuais. Brasília: CONSEA; 2010. 284 p.

10. Brasil. Ministério da Saúde. Secretaria de Vigilância em Saúde. Departamento de Vigilância de Doenças e Agravos não Transmissíveis e Promoção de Saúde. Vigitel Brasil 2014: vigilância de fatores de risco e proteção para doenças crônicas por inquérito telefônico. Brasília: Ministério da Saúde; 2015. 152 p.

11. Brasil. Ministério do Desenvolvimento Social e Combate à Fome. Identificação de perfil e avaliação dos usuários de restaurantes populares. Brasília: MDS; 2008.

12. Juiz de Fora. Secretaria Municipal de Saúde de. Plano Municipal de Saúde de Juiz de Fora - 2014-2017. Juiz de Fora: SMS; 2013. 110 p.

13. Silva AA, Pereira FF, Coelho BL. Perfil dos comensais e avaliação pelos usuários do restaurante popular João Domingos Fassarela, Governador Valadares - MG [Trabalho de Conclusão de Curso]. [Governador Valadares]: Faculdade de Ciências da Saúde da Universidade Vale do Rio Doce; 2009.

14. Mattos RM, Ferreira RF. Quem vocês pensam que (elas) são?- representações sobre as pessoas em situação de rua. Psicol Soc. 2004; 16(2):47-58.

15. Paolo ED, Ribas LA, Pereira MRR. Eutanásia social: um estudo de caso da população de rua de Juiz de Fora. CES Revista 2006; 273-293.

16. Pereira VM. População de rua em Juiz de Fora: uma reflexão a partir da questão social [Dissertação]. [Juiz de Fora]: Universidade Federal de Juiz de Fora, Programa de Pós Graduação em Serviço Social; 2007.

17. Letelier ME. Escolaridade e inserção no mercado de trabalho. Cad Pesq. 1999; (107):133-148.

18. Brasil. Ministério do Trabalho e Previdência Social. Reajuste: salário mínimo será de $\mathrm{R} \$ 880$ em 2016 [Internet]. Disponível em: http://www.previdencia.gov.br/2015/12/reajuste-salario-minimosera-de-r-880-em-2016/

19. Leal D. Crescimento da alimentação fora do domicilio. Segurança Alimentar e Nutricional 2010; 17(1):123-132.

20. Brasil. Ministério do Desenvolvimento Social e Combate à Fome. Pesquisa de opinião pública: usuários de restaurantes populares. Brasília: MDS; 2005. 
21. Dutra MMM. Fome de cidadania e o direito à alimentação: a percepção dos usuários do restaurante popular mesa do povo em Fortaleza - CE [Dissertação]. [Fortaleza]: Universidade Federal do Ceará; 2007.

22. Carvalho FMA, Amorim SS, Silva MMS, Gomes ST. Investimento social e perfil dos usuários do primeiro restaurante popular de Belo Horizonte - MG. Reuna 2007; 12(2):21-37.

23. Brasil. Ministério da Saúde. Secretaria de Atenção à Saúde. Departamento de Atenção Básica. Guia alimentar para a população brasileira. 2. ed. Brasília: Ministério da Saúde; 2014. 152 p.

24. Silva CL. Consumo de frutas e hortaliças e conceito de alimentação saudável em adultos de Brasília [Dissertação]. [Brasília]: Universidade de Brasília, Programa de Pós Graduação em Ciências da Saúde; 2011.

25. Levy RB, Claro RM, Bandoni DH, Mondini L, Monteiro CA. Disponibilidade de 'açúcares de adição' no Brasil: distribuição, fontes alimentares e tendência temporal. Rev Bras Epidemiol. 2012; 15(1):3-12.

Recebido: 29/6/2016

Revisado: 29/1/2017

Aceito: 09/02/2017 